\title{
Africanacetus from the sub-Antarctic region: The southernmost record of fossil beaked whales
}

Pavel E. Gol'din and Karina A. Vishnyakova

Acta Palaeontologica Polonica 58 (3), 2012: 445-452 doi: http://dx.doi.org/10.4202/app.2011.0097

We report two partial skulls of fossil beaked whales (Odontoceti, Ziphiidae) of uncertain age trawled from the sea floor of the sub-Antarctic Indian Ocean (58 to 60几 S), representing the southernmost record of the family. The skulls possess diagnostic features of the genus Africanacetus, several specimens of which have been recovered from the sea floor off South Africa, but differ from the type and only known species Africanacetus ceratopsis in their larger size. This difference may either reflect intraspecific variation or indicate the existence of a hitherto unrecognised species. The two specimens are characterised by unusually developed mesorostral ossifications, combined with maxillary crests occurring in the facial region. Both of the latter are found in a range of extant and extinct ziphiids, and known to be sexually dimorphic in extant beaked whales. These structures may be the result of hypermorphosis driven by sexual selection, and could be involved in male-specific behaviour.

Key words: Mammalia, Cetacea, Ziphiidae, hypermorphosis, sexual selection, Antarctic.

Pavel E. Gol'din [pavelgoldin412@gmail.com], Taurida National University, 4, Vernadsky Avenue, Simferopol, Crimea, 95007 Ukraine;

Karina A. Vishnyakova [karinavishnyakova@gmail.com], South Scientific Research Institute of Marine Fisheries and Oceanography, 2, Sverdlova St., Kerch, Crimea, 98000 Ukraine and Taurida National University, 4, Vernadsky Avenue, Simferopol, Crimea, 95007 Ukraine.

This is an open-access article distributed under the terms of the Creative Commons Attribution License (for details please see creativecommons.org), which permits unrestricted use, distribution, and reproduction in any medium, provided the original author and source are credited. 
FoF Full text $(417.5 \mathrm{kB})$ 